\title{
A TEMÁTICA AMBIENTAL NA EDUCAÇÃO CIENTÍFICA SEGUNDO AS POLÍTICAS CURRICULARES OFICIAIS BRASILEIRAS
}

\author{
ENVIRONMENTAL THEMES IN SCIENCE EDUCATION ACCORDING \\ TO BRAZILIAN OFFICIAL CURRICULUM POLICIES
}

\author{
LA THÉMATIQUE ENVIRONNEMENTALE DANS L'ÉDUCATION \\ SCIENTIFIQUE SELON LES POLITIQUES OFFICIELLES BRÉSILIENNES
}

LA TEMÁTICA AMBIENTAL EN LA EDUCACIÓN CIENTÍFICA SEGUNDO LAS POLÍTICAS CURRICULARES OFICIALES BRASILEÑAS

\section{Marlécio Maknamara da Silva Cunha*}

\section{RESUMO}

Este artigo tem como objetivo analisar a abordagem da temática ambiental indicada para $o$ ensino de Ciências pelas políticas curriculares oficiais do Brasil. Situa a reformulação curricular nacional implementada na década de 1990 no contexto das políticas públicas educacionais, associando-as à orientação neoliberal das reformas implementadas na contemporaneidade brasileira. Identifica e discute as concepçôes de Meio Ambiente e Educação Ambiental contidas em diferentes documentos dos Parametros Curriculares Nacionais, explicitando como tais parâmetros entendem a inserção da temática ambiental no currículo e ensino de Ciências. Analisa a relação estabelecida entre Educação Ambiental e ensino de Ciências segundo os referidos parâmetros, concluindo pela simplificação, antropocentrismo e utilitarismo na abordagem da temática ambiental no ensino de Ciências e pela fragmentação dos conteúdos dessa disciplina escolar.

Palavras-chave: Parâmetros Curriculares Nacionais. Ensino de Ciências. Meio Ambiente.

\footnotetext{
* Mestre em Educação pela Universidade Federal da Paraíba (2005). Doutorando em Educação na Universidade Federal de Minas Gerais. Professor Assistente do Departamento de Biologia da Universidade Federal de Sergipe (marlecio@ufmg.br). A discussão aqui apresentada é resultado do aprofundamento de uma seção integrante de um dos capítulos da dissertação de mestrado do autor.
} 


\section{INTRODUÇÃO}

A melhoria do ensino de Ciências sempre constituiu um grande desafio para os educadores e, embora tenham sido realizadas diversas pesquisas sobre diferentes aspectos inerentes ao processo de ensino-aprendizagem nessa disciplina escolar, ela está longe de obter soluções definitivas.

Diante das constatações feitas acerca de como o ensino de Ciências vem sendo desenvolvido na escola brasileira contemporânea, é necessário entender que a reflexão sobre essa disciplina escolar não deve permanecer apenas no plano da descrição de objetivos, conteúdos e metodologias para a educação científica. A análise sobre as características e problemas dessa disciplina pouco contribui para a educação escolar e a sociedade, se é tomada como um problema restrito à perspectiva interna da escola.

Assim, faz-se necessário um posicionamento sobre o ensino de Ciências diante do contexto da realidade brasileira, nos seus aspectos político, econômico e social. Esses aspectos, bem como suas relações com a educação escolar, têm nas políticas curriculares implementadas no Brasil a partir da década de 1990 um campo privilegiado para sua análise. As propostas oficiais de reformas curriculares estabelecem pressupostos políticos, econômicos e sociais relacionados ao período histórico-social em que foram formuladas.

Entendendo que as políticas públicas da educação brasileira são influenciadas por tais aspectos políticos, econômicos e sociais e que, ao mesmo tempo, influenciam as práticas pedagógicas desenvolvidas no âmbito escolar, este trabalho procura analisar a proposta dos Parâmetros Curriculares Nacionais $\left(\mathrm{PCN}^{1}\right)$ de Ciências Naturais para o terceiro e quarto ciclos do ensino fundamental, desvelando, especificamente, o direcionamento que tais parâmetros dão quanto à abordagem do Meio Ambiente no ensino de Ciências.

A temática ambiental vem constituindo alvo de debates em nível mundial, sendo crescentes as exigências de sua abordagem em âmbito escolar. É no contexto da crise ambiental ora vivenciada que a escola e outras instituições sociais são chamadas a contribuir com a superação de tal crise, por meio do desenvolvimento de práticas de Educação Ambiental (EA).

A literatura pertinente à EA, por sua vez, tem enfatizado exaustivamente que o Meio Ambiente $^{2}$ não deve ser entendido sob uma perspectiva reducionista - na qual sejam considerados apenas seus elementos físicos, químicos e biológicos -, enquanto que as práticas educativas voltadas ao mesmo não devem se restringir apenas ao tratamento pedagógico de aspectos naturais, sem considerar os aspectos políticos, econômicos e culturais das relaçôes entre sociedade e natureza. Por conseguinte, é de suma importância analisar como as políticas curriculares oficiais concebem o Meio Ambiente e sua abordagem em contexto escolar, especificamente no ensino de Ciências.

A opção pela análise do enfoque dado à temática ambiental pelos PCN de Ciências Naturais deve-se ao fato de que, conforme lembram os trabalhos de Amaral $(2001 ; 2000)$, 
Chinen (1999) e Soares (1998), a concepção de Meio Ambiente no ensino de Ciências desempenha um papel central no desenvolvimento dessa disciplina escolar. Conseqüentemente, a discussão acerca do enfoque ambiental delineado pelos referidos Parâmetros possibilita um melhor entendimento não apenas da relação entre Educação Ambiental e ensino de Ciências preconizada pelas políticas curriculares oficiais, como também um subsídio à análise de como vem sendo desenvolvida a própria disciplina de Ciências no contexto educacional brasileiro.

Para a análise a que se propõe o presente trabalho, recorre-se à proposta dos Parâmetros Curriculares Nacionais de Ciências Naturais para o terceiro e quarto ciclos do ensino fundamental e, também, a diferentes documentos dos PCN que tratam explicitamente da inserção da temática ambiental no currículo escolar.

\section{PARÂMETROS CURRICULARES NACIONAIS: CONTEXTO DE SUA FORMULAÇÃO}

Desde os primórdios da formação dos Estados Nacionais no século XVI, passou-se a perceber, de maneira mais clara, a importância da coesão social para a manutenção de uma determinada estrutura política e social. Dentre os vários caminhos que convergem no sentido da coesão social, a educação escolar ocupa lugar de destaque. É nesse âmbito que emerge a questão da formulação de currículos mínimos para as diversas modalidades de ensino, mediante a implementação de propostas curriculares nacionais.

No período mais recente da história brasileira, a partir dos anos de 1980, a definição de modificaçôes no sistema educacional (incluindo a elaboração de reformas estruturais e curriculares e definição de currículos comuns) se relaciona, também, ao contexto de redemocratização política, posterior ao período de ditadura militar vivenciado pelo Brasil. Essa tentativa de estender a redemocratização ao espaço institucional educacional reflete-se nas propostas educacionais apresentadas durante a elaboração da Constituição Federal - CF (BRASIL, 1988) e, posteriormente, no processo de definição da nova Lei de Diretrizes e Bases da Educação Nacional - LDB (BRASIL, 1996).

A despeito do momento histórico de redemocratização em que foram formuladas as políticas públicas educacionais na década de 1980, os anos 90 foram marcados por uma orientação direta do projeto neoliberal de sociedade sobre a formulação e implementação de tais políticas.

O neoliberalismo, por sua vez, consiste numa política cultural que vem impondo um amplo processo de modernização conservadora no Brasil e no mundo. Segundo Silva (2001, p. 13), "o projeto neoconservador e neoliberal envolve, centralmente, a criação de um espaço em que se torne impossível pensar o econômico, o político e o social fora das categorias que justificam o arranjo social capitalista". 
Tal arranjo político, econômico e social define-se, de maneira sintética, na aparente contradição existente na articulação entre os termos "modernização" e "conservadora". Contraditória, porque a idéia de algo que se moderniza pressupõe uma linearidade envolvendo progresso, transformação; enquanto aquilo que se conserva consiste em algo que é mantido, é tradicional. Aparente, porque tal articulação neoliberal consiste mesmo na liberação do campo econômico ao quadro do livre mercado (modernização), ao passo em que se controla o desenvolvimento de propósitos sociais, culturais e políticos (conservação).

O caráter conservador neoliberal também se reflete no conjunto de estratégias que priorizam a eleição dos padrões culturais dominantes como referenciais para a obtenção de competências que garantam a eficiência e competitividade no cenário econômico globalizado. ${ }^{3}$ Santos (2002), baseando-se nos estudos de Popkewitz (2000) sobre as reformas educacionais de caráter neoliberal - para quem estas consistem em novas formas de administração social da liberdade -, situa a implementação das reformas educacionais de cunho neoliberal no processo de legitimação dos padrões culturais dominantes e necessários à manutenção do capitalismo na atualidade:

... as reformas falam de um professor-pesquisador, um profissional reflexivo e uma criança que é construtora de conhecimentos, que tem disposiçôes flexíveis para resolução de problemas, que dispóe de uma auto-estima apropriada que lhe permite a participação adequada nas atividades escolares, enfim, uma criança que tem interesse em aprender. Para Popkewitz, essas novas propostas pedagógicas buscam apenas instalar processos de inclusão de crianças e de professores que não se encaixam nesse perfil. São novos mapas de normalização que se configuram na busca de estimular no outro, no diferente, as características internas desse novo modelo de sujeito. Trabalha-se agora com a mudança de qualidades, disposiçôes e sensibilidades interiores, instalando-se um novo tipo de governo da alma, que possibilita às pessoas agirem dentro desse novo tipo de liberdade. Uma liberdade marcada por parâmetros de governabilidade que permitem às crianças a participação na nova realidade socioeconômica, produzindo um tipo de personalidade controlada, em função das mudanças sociais e culturais que vêm ocorrendo no mundo contemporâneo (...) (SANTOS, 2002, p. 350).

É no contexto da configuração dessas reformas que os discursos oficiais no campo educacional vêm afirmando que "a educação é peça-chave para o desenvolvimento do Brasil”, "a educação é condição essencial ao exercício da cidadania e da competitividade no mundo globalizado", ou, ainda, "é preciso redefinir o papel da escola, tendo em vista as modificaçōes que têm ocorrido na atualidade”. Fica clara, assim, a afinidade entre as exigências impostas pela lógica neoliberal e o discurso do governo brasileiro em prontamente atender a tais exigências, através da educação escolar.

Entretanto, não é apenas no campo de meras intenções que o governo brasileiro vem procurando adequar o papel da escola ao novo padrão de desenvolvimento econômico mundial. É no sentido dessa adequação que foram definidas e vêm sendo implementadas reformas curriculares em nível nacional (preconizadas nas Diretrizes Curriculares Nacionais e nos Parâmetros Curriculares Nacionais) para todos os níveis e modalidades de ensino. ${ }^{4}$ 
A busca de um re-ordenamento da educação segundo os moldes neoliberais é denunciada pelo processo centralizador de elaboração dos PCN - no qual foram descartados os posicionamentos, análises e experiências de caráter mais progressista que vinham sendo desenvolvidos por professores, pesquisadores, associações científicas e outros setores da sociedade comprometidos com uma educação socialmente referenciada -, revelando o desinteresse por parte do plano político-institucional educacional brasileiro em formular tais "propostas curriculares" de maneira democrática e participativa.

Explicitando a lógica desse processo centralizador advindo do Ministério da Educação e Cultura (MEC) com a exclusão do Conselho Nacional de Educação 5 (CNE) do processo de discussão e elaboração dos PCN e das DCN, Bonamino e Martinez (2002, p. 372373) afirmam que:

... no enquadramento legal fornecido pela CF, a nova LDB e a Lei no 9.131/95, os currículos e conteúdos mínimos propostos pelo MEC teriam seu norte estabelecido pela mediação de diretrizes curriculares que deveriam ter como foro de deliberação a Câmara de Educação Básica (CEB) do CNE (...). No entanto, a divulgação da primeira versão dos $\mathrm{PCN}$ s pelo MEC, antes mesmo de os conselheiros do CNE iniciarem seu novo mandato em fevereiro de 1996, marcou um dos primeiros descompassos entre os dois órgãos de Estado. (...) A análise da forma de encaminhamento e do teor da proposta curricular enviada pelo MEC ao CNE deixa claro que se tratou de uma política construída num movimento invertido, no qual os PCNs, apesar de serem instrumentos normativos de caráter mais específico, deveriam reorientar um instrumento de caráter mais geral como as DCNs. (...) Na nossa interpretação, os desentendimentos entre o MEC e o CNE em torno das definições curriculares ilustram a lógica implícita à política educacional do governo, a partir da segunda metade dos anos de 1990: excessiva centralização das decisóes do governo federal e escasso envolvimento das outras instâncias político-institucionais e da comunidade científica com a educação básica.

\section{OS PARÂMETROS CURRICULARES NACIONAIS E A TEMÁTICA AMBIENTAL}

Publicados em 1998, os PCN constituem o documento oficial que expressa a "proposta" de reorientação curricular ${ }^{6}$ para o ensino fundamental no Brasil. Com relação ao terceiro e quarto ciclos - os quais correspondem aos anos finais deste nível de ensino -, a Secretaria de Educação Fundamental do MEC organizou os PCN em dez volumes - referentes a cada uma das oito áreas de conhecimento definidas para estes ciclos -, incluindo um documento introdutório e um volume referente aos temas transversais (os quais envolvem assuntos relativos a ética, meio ambiente, saúde, orientação sexual, pluralidade cultural e trabalho e consumo).

Os temas transversais dizem respeito às grandes questôes sociais que afligem a humanidade na era contemporânea, não devendo ser abordados como mais uma disciplina escolar, e sim como um "conjunto de temas que aparecem transversalizados, permeando a concepção das diferentes áreas, seus objetivos, conteúdos e orientações didáticas" (BRASIL, 1998a, p. 65). 
Um desses temas transversais é o de Meio Ambiente, o qual indica de que maneira a temática ambiental deve ser integrada ao currículo escolar. $\mathrm{O}$ documento referente a este tema transversal ressalta o que estudos e eventos nacionais e internacionais ligados à Educação Ambiental (como a Conferência de Tbilisi ${ }^{7}$ e a Rio-92, ${ }^{8}$ por exemplo) vinham defendendo, no tocante à abrangência das questôes ambientais, com relação à necessidade de partir-se de questões locais, mas pensando sua inserção a nível global (BRASIL, 1998a).

O documento introdutório aos PCN para o terceiro e quarto ciclos do ensino fundamental afirma que "a principal função do trabalho com o tema Meio Ambiente é contribuir para a formação de cidadãos conscientes, aptos a decidir e atuar na realidade socioambiental de modo comprometido com a vida..." (idem, p. 67). Desta forma, inicialmente, a proposta dos PCN para o desenvolvimento de atividades pedagógicas que abordem a temática ambiental parece ser abrangente e progressista, ao mencionar o compromisso com a vida em geral.

Entretanto, o texto prossegue afirmando que, para esta abordagem, "é necessário que, mais do que informações e conceitos, a escola se proponha a trabalhar com atitudes, com formação de valores, com o ensino e a aprendizagem de habilidades e procedimentos. Esse é um grande desafio para a educação" (idem, p. 67-68, grifos meus).

Com isso, não obstante a defesa do trabalho pedagógico de atitudes e valores, os PCN não deixam claro que concepçôes de atitude e que tipos de valores devem ser privilegiados na abordagem dessa temática. Atitudes, segundo esses parâmetros, estariam restritas à noção de comportamento ou seriam entendidas como tendência mental para perceber as coisas de determinada maneira? Os valores, uma vez trabalhados, deveriam estar orientados para um simples "adestramento" relativo a açôes reparadoras de efeitos poluentes, ou para novas formas de relação entre o homem e natureza não-humana? Qual o conteúdo, enfim, da educação ambiental preconizada pelos PCN?

Alguns desses questionamentos podem encontrar resposta na afirmação de que “comportamentos 'ambientalmente corretos' serão aprendidos na prática do dia-a-dia na escola: gestos de solidariedade, hábitos de higiene pessoal e dos diversos ambientes, participação em pequenas negociações podem ser exemplos disso" (BRASIL, 1998a, p. 68). Parte dos questionamentos supracitados também é respondida nos parágrafos iniciais da apresentação do tema transversal Meio Ambiente, os quais constatam que

São grandes os desafios a enfrentar quando se procura direcionar as açôes para a melhoria das condições de vida no mundo. Um deles é relativo à mudança de atitudes na interação com o patrimônio básico para a vida humana: o meio ambiente.

Os alunos podem ter nota 10 nas provas, mas, ainda assim, jogar lixo na rua, pescar peixesfêmeas prontas para reproduzir, atear fogo no mato indiscriminadamente, ou realizar outro tipo de ação danosa, seja por não perceberem a extensão dessas ações ou por não se sentirem responsáveis pelo mundo em que vivem (BRASIL, 1998b, p. 169, grifos meus). 
Desta forma, é explícito o teor antropocêntrico ${ }^{10}$ e preservacionista que deve orientar a formação destas "atitudes", quando do trabalho com a temática ambiental. Ainda assim, é necessário perguntar: que condições de vida seriam essas? Melhoria para quem? Quais as estratégias e que tipo de sociedade e relação desta com a natureza estariam associadas a esta melhoria? Tais questionamentos dizem respeito à orientação que se pretende dar à educação ambiental e de como ela deve ser realizada.

A Educação Ambiental é referenciada, explicitamente, nos PCN, no documento introdutório desses parâmetros ( $2^{a}$ parte, seção de Meio Ambiente) e no documento dedicado ao detalhamento dos princípios, objetivos e conteúdos do tema transversal Meio Ambiente. Neste último, encontram-se organizados os conteúdos de EA para o terceiro e quarto ciclos do ensino fundamental, através dos seguintes blocos:

a) A natureza 'cíclica' da Natureza: constitui o bloco que abrange conteúdos referentes aos ciclos biogeoquímicos, da dinâmica de ecossistemas sob a perspectiva de estudos relativos à extinção de espécies, alterações irreversíveis nos ecossistemas, enfocando apenas aspectos naturais do meio ambiente;

b) Sociedade e meio ambiente: abrange questões relativas à relação sociedade/natureza, a partir das variações desta relação em função de aspectos culturais;

c) Manejo e conservação ambiental: reúne conteúdos referentes à busca de formas de manejo e conservação que auxiliem na construção de um desenvolvimento sustentável, crítica ao uso de técnicas contrárias à sustentabilidade, monitoramento do crescimento urbano e rural, monitoramento de queimadas, gerenciamento do lixo e saneamento. Abrange, ainda, os aspectos legais relativos à conservação ambiental.

Sobre como seriam desenvolvidas as atividades de EA, um ponto destacado pelos PCN é a importância de os professores e alunos tomarem as atividades de EA como veículo de construção de sua própria cidadania. Entretanto, a concepção de cidadania, bem como as formas pelas quais ela deve ser construída, segundo indicação dos PCN, não parecem ir ao encontro das concepções mais emancipatórias de cidadania e EA:

Como esse campo temático é relativamente novo no ambiente escolar, os professores podem priorizar sua própria formação/informação à medida que as necessidades se configurem.

(...) $\mathrm{O}$ acesso a novas informações permite repensar a prática. É nesse fazer e refazer que é possível enxergar a riqueza de informaçôes, conhecimentos e situaçóes de aprendizagem geradas por iniciativa dos próprios professores. Afinal, eles também estão em processo de construção de saberes e de açôes no meio ambiente, como qualquer cidadão. Sistematizar e problematizar suas vivências, e práticas, à luz de novas informações contribui para o reconhecimento da importância do trabalho de cada um, permitindo assim a construção de um projeto consciente de educação ambiental.

Ou seja, as atividades de educação ambiental dos professores são aqui consideradas no àmbito do aprimoramento de sua cidadania, e não como algo inédito de que eles ainda não estão participando. Afinal, a própria inserção do indivíduo na sociedade implica algum tipo de participação, de direitos e deveres com relação ao ambiente (idem, p. 188-189, grifos meus). 
Sob essa vertente, o fazer educativo ambiental e a concepção de cidadania a ser construída nesse processo educativo, pautados em um professor dotado de iniciativa para auto-motivação e auto-formação, quando situados nas atuais condições de trabalho dos professores brasileiros, deixam transparecer a orientação neoliberal desse processo. Ainda que os PCN, logo adiante, reconheçam a "necessidade de capacitação permanente do quadro de professores, da melhoria das condiçôes salariais e de trabalho, assim como a elaboração e divulgação de materiais de apoio e que sem essas medidas, a qualidade desejada fica apenas no campo das intençôes" (BRASIL, 1998b, p. 189), sabe-se do abismo existente entre o simples reconhecimento e a materialização desse reconhecimento na forma de condições de trabalho adequadas.

Outra controvérsia relativa à abordagem do tema Meio Ambiente no currículo escolar refere-se à integração desse tema com as diferentes disciplinas do ensino fundamental. De acordo com os PCN, o tratamento transversal dessa temática deve considerar que "as áreas de Ciências Naturais, História e Geografia são as tradicionais parceiras para o desenvolvimento dos conteúdos aqui relacionados, pela própria natureza dos seus objetos de estudo" (idem, p. 194).

Desta forma, apesar de o tema Meio Ambiente dever impregnar toda a prática educativa, nas diversas áreas de conhecimento, de modo a criar uma visão global e abrangente da questão ambiental (BRASIL, 1998b), os próprios PCN elegem algumas áreas como preferenciais para a abordagem dessa temática. Tal predileção baseia-se no entendimento de que os objetos de estudo dessas áreas seriam "mais ambientais" que os das outras áreas.

Essa postura significa uma forma de legitimar oficialmente que a temática ambiental é "propriedade" de uma ou algumas disciplinas escolares, o que, na visão de autoras como Brügger (1999) e Sato (2003), corresponde a um equívoco no entendimento da dinâmica do meio ambiente e de como essa temática deve ser abordada em contexto escolar. Além disso, contribui para a perpetuação do senso comum de que é a disciplina de Ciências responsável por desenvolver "atividades de Educação Ambiental".

Assim, faz-se necessário analisar os eixos de sustentação dos Parâmetros Curriculares Nacionais de Ciências Naturais, tomando sua concepção de Meio Ambiente como referencial para uma melhor compreensão do ensino dessa disciplina e de sua relação com a educação ambiental, de acordo com o que preconizam os PCN.

\section{A CONCEPÇÃO DE MEIO AMBIENTE NOS PCN DE CIÊNCIAS NATURAIS}

Os Parâmetros Curriculares Nacionais de Ciências Naturais, enquanto política curricular centralizadora, foram formulados visando se sobrepor às propostas curriculares estaduais de Ciências até então vigentes.

Os PCN de Ciências têm a educação ambiental, a educação em saúde e a educação tecnológica como seus três grandes eixos de sustentação, os quais deverão ser tratados 
pedagogicamente por intermédio de quatro eixos temáticos: Terra e Universo, Ser Humano e Saúde, Tecnologia e Sociedade e Vida e Meio Ambiente.

Considerando que a concepção de Meio Ambiente no ensino de Ciências é reveladora de como esta disciplina é desenvolvida (AMARAL, 2000; CHINEN, 1999; SOARES, 1998), faz-se necessário identificar e analisar como esta concepção permeia os PCN de Ciências.

Inicialmente, o entendimento dos PCN de Ciências acerca do que vem a ser Meio Ambiente pode ser compreendido a partir da relação que tais parâmetros fazem do ensino de Ciências com a temática ambiental:

São muitas as conexōes entre Ciências Naturais e Meio Ambiente. Considerando conhecimentos cientificos como essenciais para o entendimento das dinâmicas da natureza, em escala local e planetária, Ciências Naturais promove a educação ambiental, em todos os eixos temáticos (BRASIL, 1998c, p. 51, grifos meus).

Afirmando que o ensino de Ciências promove a educação ambiental por proporcionar o entendimento das dinâmicas da natureza, os PCN de Ciências imprimem um reducionismo à temática ambiental ao confundir meio ambiente e natureza como representações de igual abrangência. Esse reducionismo vem sendo enfaticamente criticado pela literatura na área de Educação Ambiental (cf. CARVALHO, 2004; REIGOTA, 1998; SATO, 2003). Lima (1999), ao debater relações entre meio ambiente e educação tendo como fio condutor uma análise crítica acerca de propostas educacionais voltadas à temática ambiental, observa que tais propostas têm sido reducionistas ao enfatizar "os aspectos técnicos e biológicos da educação e da questão ambiental em detrimento de suas dimensões políticas e éticas" (p. 136).

Relacionada a esse reducionismo também fica evidente uma visão cientificista ${ }^{11} \mathrm{com}$ que se pretende entender a dinâmica da natureza. A respeito do viés cientificista dos referidos documentos, é possível percebê-lo, por exemplo, quando o meio ambiente é tomado como sinônimo de habitat, ao afirmar-se que "a comparação de ambientes, uma prática proposta por 'Vida e Ambiente' para todos os ciclos, comporta o estudo especial dos seres vivos habitantes destes ambientes, buscando-se descrever e compreender diferentes formas de vida" (idem, p. 43-44).

Nota-se, assim, o prestígio que é atribuído aos procedimentos de descrição e compreensão dos diferentes seres vivos, atividades típicas da taxonomia e sistemática biológicas, que aqui ganham relevo como procedimentos privilegiados para comparação de ambientes, entendidos como habitats. Ao fazer referência ao predomínio de perspectivas biológicas em propostas de EA, Grün (2002, p. 105) ressalta que essa inclinação reducionista, "ao confinar a educação ambiental quase exclusivamente ao ensino de biologia, acaba por reduzir a abordagem necessariamente complexa, multifacetada, ética e política das questôes ambientais aos seus aspectos biológicos". 
Por outro lado, se é razoável concordar que Ciências constitui uma disciplina que oferece conhecimentos detalhados sobre os diferentes elementos e processos que fazem parte da dinâmica dos aspectos naturais - tal como é posto pelos PCN dessa disciplina escolar -, esse detalhamento se justificaria em função de uma outra característica a respeito da abordagem do meio ambiente nos referidos documentos: o utilitarismo. ${ }^{12}$ A visão utilitarista dos documentos em questão pode ser percebida abaixo:

Nas cidades, lixo nas ruas pode significar bueiros entupidos e água de chuva sem escoamento, favorecendo as enchentes e a propagação de moscas, ratos e a veiculação de doenças. Por sua vez, o desperdício de materiais pode significar a intensificação de extração de recursos naturais, como petróleo e vegetais, que são matérias-primas para a produção de plásticos e papel. A valorização da reciclagem e o repúdio ao desperdício são exemplos de conteúdos de Ciências Naturais também essenciais a Meio Ambiente e Trabalho e Consumo.

(...) É necessário evitar o reducionismo biológico, ou seja, acreditar que o conhecimento das relaçôes do ser humano com o meio pode ser entendido com base nas relações de outras espécies. Essas análises são úteis nos estudos sobre processos naturais que atingem a espécie humana, como relaçōes de parasitismo e seleção natural (BRASIL, 1998c, p. 44, grifos meus).

Assim, a noção que emerge da análise dos PCN de Ciências é a de que o objetivo maior de se conhecer detalhadamente a natureza está nos benefícios que isto pode trazer exclusivamente ao ser humano. Nesse sentido, Ciências deveria proporcionar atenção a múltiplos fenômenos naturais e a processos de degradação não pelo valor que a compreensão da dinâmica natural traz em si, mas porque é preciso utilizar a natureza com parcimônia (reciclando, não desperdiçando), de forma a não ameaçar a continuidade dessa relação de uso e a não menosprezar aquilo que atinge a espécie humana, unicamente.

Colocando os conhecimentos científicos como "essenciais", os PCN de Ciências parecem ignorar um importante pressuposto no campo da EA, qual seja o de que a complexidade inerente à dinâmica ambiental requer, necessariamente, uma abordagem interdisciplinar (cf. CARVALHO, 2004; SATO, 2000), não se justificando, portanto, essa pretensa essencialidade de conhecimentos científicos diante de uma questão que exige a valorização das mais variadas formas de saber (SATO, 2003).

É inadmissível, portanto, cogitar que a educação ambiental possa acontecer, ainda que no ensino de Ciências, levando em consideração apenas aspectos naturais, e que se pretenda explicar esta dinâmica sob um enfoque meramente utilitarista e cientificista. Fracalanza (1992) apontava, já no início da década de 1990, a expectativa pelo conhecimento científico-ecológico enquanto assegurador da proteção ambiental, como uma característica do cientificismo ligado à Educação Ambiental.

As relações entre cientificismo e temática ambiental nos PCN de Ciências são ainda reveladas na própria estrutura desses documentos: por um lado, na concepção retrógrada de que Ciências constitui, por excelência, a disciplina responsável por tratar de temas de meio ambiente; por outro, a partir da presença do tema Meio Ambiente como eixo do ensino de Ciências, além de ser um tema transversal. 
Com relação a este último aspecto, Amaral (2001, p. 84) lembra que:

os temas transversais Meio Ambiente e Saúde também estão presentes de forma destacada na estrutura curricular dos Parâmetros de Ciências, confirmando a antiga tendência de associar predominantemente esses assuntos ao ensino das Ciências Físicas e Naturais.

Ou seja: por considerar Ciências como preferencial para a abordagem da temática ambiental, o meio ambiente, nessa disciplina, deve estar presente como algo além de um tema transversal, deve constituir todo um eixo para tal disciplina.

Por conseguinte, se o tema Meio Ambiente, segundo os PCN de Ciências, deve aparecer como eixo de todo o ensino da mesma, mas, ao mesmo tempo, deve ser tratado apenas como tema transversal, temos um impasse acerca de como o professor de Ciências deve desenvolver a educação ambiental nessa disciplina escolar. Conforme visto anteriormente, os próprios PCN afirmam que a EA deve impregnar toda a prática educativa nas disciplinas escolares, o que poderia estar refletido, no ensino de Ciências, com a tomada de Meio Ambiente como eixo temático; entretanto, é possível a interpretação de que a temática ambiental esteja presente ao longo da disciplina, mas de maneira pontual, através de projetos envolvendo o tema transversal Meio Ambiente. Esta última interpretação encontra sintonia com o documento de apresentação dos temas transversais, o qual, defendendo a inserção curricular destes temas através de projetos, afirma que:

Os projetos são uma das formas de organizar o trabalho didático, que pode integrar diferentes modos de organização curricular. Pode ser utilizado, por exemplo, em momentos específicos do desenvolvimento curricular de modo a envolver mais de um professor e uma turma, articular o trabalho de várias áreas, ou realizar-se no interior de uma única área.

(...) Este tipo de organização permite que se dê relevância às questôes dos Temas Transversais, pois os projetos podem se desenvolver em torno deles e ser direcionados para metas objetivas, com a produção de algo que sirva como instrumento de intervenção nas situaçôes reais (BRASIL, 1998b, p. 41).

Além disso, ao citar critérios de seleção de conteúdos de Ciências Naturais para o terceiro e quarto ciclos do ensino fundamental, os PCN de Ciências destacam que:

... os conteúdos devem ser relevantes do ponto de vista social, cultural e científico, permitindo ao estudante compreender, em seu cotidiano, as relaçóes entre o ser humano e a natureza mediadas pela tecnologia, superando interpretaçôes ingênuas sobre a realidade à sua volta. Os temas transversais apontam conteúdos particularmente apropriados para isso (BRASIL, 1998c, p. 35, grifos meus).

Assim, apesar de o discurso ser o de que a EA deve permear toda a prática pedagógica nas diferentes disciplinas escolares, a educação ambiental parece ser indicada pelos PCN como simples atividades esporádicas no ensino de Ciências.

Por fim, outra simplificação existente na estrutura dos PCN de Ciências - a qual termina por revelar uma concepção reducionista de Meio Ambiente e, por conseqüência, de Educação Ambiental - refere-se ao fato de esses parâmetros elencarem os eixos Terra 
e Universo, Ser Humano e Saúde e Tecnologia e Sociedade de maneira separada do de Vida e Ambiente, como se a Terra, o ser humano que nela habita e a saúde deste não fizessem parte do meio ambiente (AMARAL, 2001). A mesma simplificação ocorre no conjunto de temas transversais, quando fica subentendido que Pluralidade Cultural, Ética, Orientação Sexual, Trabalho e Consumo não pertencem ao meio ambiente.

Dessa forma, no intuito de contribuir com a concretização da Educação Ambiental no âmbito escolar através da disciplina de Ciências, os PCN terminam por encaminhar visões reducionistas do meio ambiente e da EA, simplificando, assim, a maneira como a problemática ambiental pode ser abordada na referida disciplina escolar.

Os reducionismos, nesse caso, se expressam através da compreensão de Meio Ambiente como sinônimo de Natureza, a qual deve ser exaustiva e exclusivamente estudada pela Ciência com vistas ao seu usufruto pelo homem. Há, portanto, nos documentos analisados, um cientificismo com que se pretende compreender e explicar a dinâmica ambiental e um utilitarismo com que se advoga a necessidade dessa compreensão e intervenção sobre o meio ambiente. Em decorrência dos reducionismos apresentados, há uma simplificação quanto à abordagem do meio ambiente, quer no privilégio dado à disciplina de Ciências, quer na consideração de seus "conteúdos mais ambientais" ou, ainda, nas atividades prescritas pelos PCN para dar cabo ao entendimento da dinâmica ambiental através da referida disciplina escolar.

Ambos, reducionismos e simplificações, constituem um grande obstáculo ao desenvolvimento de práticas pedagógicas voltadas à superação da crise ambiental que ora vivenciamos.

\section{CONSIDERAÇÕES FINAIS}

Os Parâmetros Curriculares Nacionais emergem no contexto educacional brasileiro como política curricular centralizadora de orientação neoliberal que procura adequar os saberes escolares às exigências do mercado e as práticas pedagógicas dos professores às condições que o próprio mercado impóe à escola.

A concepção de Meio Ambiente apresentada pelos PCN de Ciências preserva formas reducionistas e cientificistas de abordagem das questóes ambientais ao excluir seus fatores políticos e ideológicos. A perspectiva cientificista e o culto à tecnologia defendidos pelos referidos parâmetros garantem o instrumental com que o ser humano, de maneira antropocêntrica e utilitarista, relacionar-se-á com a natureza não-humana.

Apesar de os PCN afirmarem que a temática ambiental deve permear todo o conteúdo das diferentes disciplinas escolares, nota-se que os referidos parâmetros elegem algumas áreas como preferenciais para o tratamento dessa temática, como é o caso da disciplina de Ciências. Nesta, ao se perpetuar a fragmentação de conteúdos que, invariavelmente, dizem respeito ao meio ambiente, termina-se por simplificar o debate acerca da dinâmica ambiental, implicando um enfoque legitimador da ordem sócio-ambiental vigente. 


\section{Notas}

1. A forma abreviada da expressão Parâmetros Curriculares Nacionais não será grafada, neste trabalho, com "s", pelo fato de a sigla PCN possibilitar tanto sua leitura no plural como no singular. O mesmo valerá para siglas como $D C N$, por exemplo, cuja possibilidade de leitura é similar.

2. Aqui entendido como "o lugar determinado ou percebido, onde os elementos naturais e sociais estão em relações dinâmicas e em interação. Essas relações implicam processos de criação cultural e tecnológica e processos históricos e sociais de transformação do meio natural e construído" (REIGOTA, 2001, p. 14).

3. Entendendo globalização como um processo caracterizado pela desregulamentação dos mercados nacionais, racionalização dos processos produtivos, difusão universal dos padrões de produção e consumo e acentuação do monopólio dos avanços científicos e das novas tecnologias, o qual acarreta alterações nos campos econômico, político, social e cultural em nível global.

4. Além das diretrizes e parâmetros mencionados, podem ser citados outros dispositivos, como o Programa Nacional do Livro Didático (PNLD), o Sistema Nacional de Avaliação da Educação Básica (Saeb), o Programa Parâmetros em Ação, o Exame Nacional do Ensino Médio (Enem), o Exame Nacional de Cursos ("Provão") - este, reformulado e atualmente denominado Sistema Nacional de Avaliação do Ensino Superior (Sinaes) -, que, juntos, conferem organicidade às políticas públicas educacionais que vêm sendo implementadas.

5. Criado pela Lei no 9.131/95 como órgão representativo da sociedade brasileira, devendo ter um caráter consultivo e deliberativo sobre as propostas do MEC, possibilitando a este uma aproximação maior da realidade educacional nacional (BONAMINO; MARTÍNEZ, 2002).

6. Acerca do pretenso caráter meramente sugestivo que os Parâmetros Curriculares Nacionais anunciam ter, Moreira (1996) critica o eufemismo inerente à utilização do termo "parâmetro", diante das tentativas de instituição de um currículo nacional a partir dos inúmeros detalhamentos e recomendações feitos por tais documentos.

7. Cf. Unesco (1980).

8. Conferência das Nações Unidas sobre Meio Ambiente e Desenvolvimento, realizada em 1992, na cidade do Rio de Janeiro. Também conhecida como ECO-92. Na ocasiāo da ECO-92, foi formulado o Tratado de Educação Ambiental para sociedades sustentáveis e responsabilidade global, importante documento orientador da Educação Ambiental brasileira e que se encontra, na íntegra, em Carvalho (2004).

9. Paula Brügger (1999), em seu livro Educação ou adestramento ambiental?, lança um importante alerta a respeito de práticas de Educação Ambiental que vêm sendo implementadas sob uma perspectiva comportamentalista. Segundo a autora, o comportamentalismo na EA privilegia o reforço de comportamentos "ambientalmente corretos", adestrando mais do que efetivamente educando. $\mathrm{O}$ adestramento se identifica com a execução de determinadas tarefas que, no caso da EA, levam a ajustamentos dos indivíduos a condições ambientais degradantes. Carvalho (2004), concordando com Brügger, ressalta que o adestramento ambiental, com sua dimensão normativa e disciplinar, produz efeitos pouco estimulantes para uma EA que se pretende emancipatória, libertária e criativa. 10. Uma postura antropocêntrica é definida como aquela em que o homem é considerado o centro de tudo e na qual todas as coisas existem única e exclusivamente em função dele (GRÜN, 2002). 
11. A idéia de cientificismo na Educação Ambiental, segundo autores como Brügger (1999), Cabral (2000) e Fracalanza (1992), remete a uma visão onde predomina o instrumentalismo (inaugurado pelo pensamento moderno) no entendimento do ambiente e na resolução dos problemas ambientais. Considerando como válidos somente os pensamentos e ações referentes ao ambiente que sejam respaldados pelo conhecimento científico, o cientificismo caracteriza-se pela idéia de supremacia da Ciência sobre outras formas de conhecimento e pela ênfase nas benfeitorias da Ciência e da Tecnologia, descartando seus limites de compreensão do mundo e de seus fracassos (AMARAL, 1995).

12. O utilitarismo - intrinsecamente relacionado ao antropocentrismo -, baseado na idéia de natureza criada para uso indiscriminado pelo homem, fundamenta-se na perspectiva da utilidade da natureza não-humana para o ser humano. Assim, o utilitarismo considera a natureza apenas quanto ao seu valor de uso (GRÜN, 2002).

\section{Referências}

AMARAL, Ivan Amorosino do. Educação ambiental e ensino de ciências: uma história de controvérsias. Pro-Posiçôes, Campinas, v. 12, n. 1 [34], p. 73-93, mar. 2001.

Currículo de ciências: das tendências clássicas aos movimentos atuais de renovação. In: BARRETTO, Elba Siqueira de Sá (Org.). Os currículos do ensino fundamental para as escolas brasileiras. 2. ed. Campinas: Autores Associados, 2000. p. 201-232.

. Em busca da planetização: do ensino de Ciências para a Educação Ambiental. 1995. $434 f$. Tese (doutorado), Faculdade de Educação, Universidade Estadual de Campinas, Campinas, SP, Brasil.

BONAMINO, Alicia; MARTÍNEZ, Silvia Alícia. Diretrizes e Parâmetros Curriculares Nacionais para o Ensino Fundamental: a participação das instâncias políticas do Estado. Educação e Sociedade, Campinas, v. 23, n. 80, p. 371-388, set. 2002.

BRASIL, Constituição da República Federativa do Brasil. São Paulo: Saraiva, 1988.

. Lei de Diretrizes e Bases da Educação Nacional. Lei n. 9.394, de 20 dez. 1996. Diário Oficial da União, Brasília, 23 dez. 1996, p. 27.894.

- Ministério da Educação e do Desporto. Parâmetros Curriculares Nacionais - terceiro e quarto ciclos do ensino fundamental: documento introdutório. Brasília: SEF/MEC, 1998a.

Parâmetros Curriculares Nacionais - terceiro e quarto ciclos do ensino fundamental: apresentação dos temas transversais. Brasília: SEF/MEC, $1998 \mathrm{~b}$.

- Parâmetros Curriculares Nacionais - terceiro e quarto ciclos do ensino fundamental: ciências naturais. Brasília: SEF/MEC, 1998c.

BRÜGGER, Paula. Educação ou adestramento ambiental? 2. ed. Florianópolis: Letras Contemporâneas, 1999.

CABRAL, Maria Conceição Rosa. O Paradigma Mecanicista e a Educação Ambiental nas diretrizes curriculares de Ciências do Estado do Pará. 2000. 120f. Dissertação (mestrado), Faculdade de Educação, Universidade Estadual de Campinas, Campinas, SP, Brasil. 
CARVALHO, Isabel C. de Moura. Educação ambiental: a formação do sujeito ecológico. São Paulo: Cortez, 2004.

CHINEN, Jorge. $O$ ambiente e o ensino de ciências: a fala do professor como um dos elementos de sua formação continuada. 1999. 231f. Dissertação (mestrado), Faculdade de Educação. Universidade Estadual de Campinas, Campinas, SP, Brasil.

FRACALANZA, Dorotea C. Crise ambiental e ensino de ecologia: o conflito na relação homemmundo natural. 1992. 314f. Tese (doutorado), Faculdade de Educação, Universidade Estadual de Campinas, Campinas, SP, Brasil.

GRÜN, Mauro. Ética e Educação Ambiental: a conexão necessária. 5. ed. Campinas: Papirus, 2002.

LIMA, Gustavo F. da Costa. Questão ambiental e educação: contribuições para o debate. Ambiente \& Sociedade, Campinas, ano II, n. 5, p. 135-153, 1999.

MOREIRA, Antonio F. Barbosa. Os Parâmetros Curriculares Nacionais mais uma vez em questão. In: BICUDO, Maria A. Viggiani; SILVA JÚNIOR, Celestino A. (Orgs.). Formação do educador: dever do estado, tarefa da universidade. São Paulo: EdUnesp, 1996. p. 97-110.

POPKEWITZ, Thomas S. Reforma, conhecimento pedagógico e administração social da individualidade: a educação escolar como efeito do poder. In: IMBERNÓN, Francisco. A educação no século XXI: os desafios do futuro imediato. Porto Alegre: Artmed, 2000. p. 141- 169.

REIGOTA, Marcos. Meio ambiente e representação social. 4. ed. São Paulo: Cortez, 2001. O que é Educação Ambiental. São Paulo: Brasiliense, 1998.

SANTOS, Lucíola L. de C. Paixão. Políticas públicas para o ensino fundamental: Parâmetros Curriculares Nacionais e Sistema Nacional de Avaliação (Saeb). Educação e Sociedade, Campinas, v. 23, n. 80, p. 349-370, set. 2002.

SATO, Michèle. Educação ambiental. São Carlos: Rima, 2003.

Dialogando saberes na Educação Ambiental. In: Encontro Paraibano de Educação Ambiental - Novos Tempos, 08-10 de novembro, 2000. Anais, seção "palestras". João Pessoa: REA/PB \& UFPB, 2000. P. 1-11.

SILVA, Tomaz Tadeu da. A 'nova' direita e as transformações na pedagogia da política e na política da pedagogia. In: ; GENTILI, Pablo A. A. (Orgs.). Neoliberalismo, qualidade total e educação: visões críticas. 10. ed. Petrópolis: Vozes, 2001. p. 9-29.

SOARES, Míriam Ester. Concepçôes de ambiente e educação ambiental em professores de ciências: múltiplos significados? 1998. 179f. Dissertação (mestrado), Faculdade de Educação, Universidade Federal de Minas Gerais, Belo Horizonte, MG, Brasil.

UNESCO. La educación ambiental: las grandes orientaciones de la Conferencia de Tbilisi. Paris: ONU, 1980. 


\section{Environmental themes in science education according to brazilian official curriculum policies}

Abstract

This article aims at analysing the approach to environmental themes indicated for science teaching according to official curriculum policies in Brazil. It places the reformulation of national curriculum implemented in the decade of 1990 in the context of educational public policies, associating them to the neoliberal reforms carried out in Brazilian contemporaneity. Identifies and discusses the conceptions of Environment and Environmental Education contained in different documents of Brazilian Curriculum Parameters, showing how these parameters comprehend the insertion of environmental topics in the curriculum and science teaching. It also analyses the relationship between Environmental Education and science teaching according to these parameters, concluding on the use of simplification, anthropocentrism and utilitarianism in the environmental themes in science teaching and the fragmentation of the contents of this school subject.

Keywords: Brazilian Curriculum Parameters. Science teaching. Environment.

\section{La thématique environnementale dans l'éducation scientifique selon les politiques officielles brésiliennes} Résumé

Cet article vise l'analyse de l'approche de la thématique environnementale indiquée pour l'enseignement des sciences dans les politiques curriculaires officielles du Brésil. Il situe la reformulation du curriculum national implémentée dans les années 1990 dans le contexte des politiques publiques éducationnelles, en les associant à l'orientation néolibérale des reformes implémentées dans la contemporanéité brésilienne. Il identifie et discute les conceptions de l'Environnement et de l'Éducation sur l'Environnement contenues dans les différents documents des Paramètres Curriculaires Nationaux, explicitant comment de tels paramètres comprennent l'insertion de la thématique de l'environnement dans le curriculum et l'enseignement des sciences selon les paramètres en question, concluant par la simplification, anthropocentrisme et utilitarisme dans l'approche de la thématique de l'environnement dans l'enseignement des sciences et par la fragmentation des contenus de cette matière scolaire.

Mots clefs : Paramètres curriculaires brésiliens. Enseignement des sciences. Environnement.

\section{La temática ambiental en la educación científica segundo las políticas curriculares oficiales brasileñas Resumen}

Este artículo tiene como objectivo analisar el abordaje de la temática ambiental indicada a la enseñan$z a$ de ciencias por las políticas curriculares oficiales de Brasil. Situa la reformulación curricular nacional implementada en la década de 1990 en el contexto de las politicas públicas educacionales, asociándolas a la orientación neoliberal de las reformas implementadas en la contemporaneidad brasileña. Identifica y discute las concepciones de ambiente y educación ambiental contenidas en distintos documentos de los parámetros curriculares nacionales, explicitando como tales parámetros entenden la inserción de la temática ambiental en el currículo y enseñanza de ciencias. Analisa la relación establecida entre educación ambiental y enseñanza de ciencias segundo los referidos parámetros, concluyendo por la simplificación, antropocentrismo y utilitarismo en el abordaje de la temática ambiental en la enseñanza de ciencias y por la fragmentación de los contenidos de esta asignatura escolar.

Palabras-clave: Parámetros curriculares nacionales. Enseñanza de ciencias. Ambiente.

Recebida I ${ }^{\text {a }}$ versão em: 30.05.2007

Aceita $2^{\text {a }}$ versão em: 13.04 .2008 